\title{
Validation of neuromuscular blocking agent use in acute respiratory distress syndrome: a meta-analysis of randomized trials
}

\author{
Wei Chang, Qin Sun, Fei Peng, Jianfeng Xie, Haibo Qiu and Yi Yang * (D)
}

\begin{abstract}
Background: We aimed to synthesize up-to-date trials to validate the effects of neuromuscular blocking agent (NMBA) use in patients with moderate-to-severe acute respiratory distress syndrome (ARDS).

Methods: Several databases including PubMed, EMBASE, Web of Science, and Cochrane Central Register were searched up to November 14, 2019. All randomized trials investigating the use of NMBAs in patients with moderate-to-severe ARDS and reporting mortality data were included in the meta-analysis. The primary outcome was mortality, and the secondary outcomes were clinical outcomes, including respiratory physiological parameters, incidence of barotrauma, ICU-free days, and ventilation-free days.

Results: A total of 7 trials enrolling 1598 patients were finally included in this meta-analysis. The results revealed that the use of NMBAs in moderate-to-severe ARDS could significantly decrease the mortality truncated to day 28 (RR 0.74, 95\% Cl 0.56 to $0.98, P=0.03$ ) and day 90 (RR $0.77,95 \% \mathrm{Cl} 0.60$ to $0.99, P=0.04$ ). NMBA use could significantly decrease the incidence of barotrauma (RR $0.56,95 \% \mathrm{Cl} 0.36$ to $0.87, P=0.009$ ). No significant difference was observed in ICU-free days or ventilation-free days between the NMBA and control groups.

Conclusion: The use of NMBAs could significantly decrease mortality in moderate-to-severe ARDS patients and decrease the incidence of barotrauma during mechanical ventilation. However, more large-scale randomized trials are needed to further validate the effect of NMBA use in ARDS.
\end{abstract}

Keywords: Acute respiratory distress syndrome, Neuromuscular blocking agent, ARDS, NMBA, Mortality

\section{Background}

Acute respiratory distress syndrome (ARDS) is defined as diffuse alveolar epithelial damage due to a dysregulated inflammatory response of intrapulmonary origin or to a systemic inflammatory process, resulting in refractory hypoxemia, reduced pulmonary compliance, and bilateral pulmonary infiltrates on chest imaging $[1,2]$. ARDS represents approximately one-tenth of all intensive care unit (ICU) admittances, and its mortality surpasses $40 \%$ once it deteriorates to severe ARDS, which is a great challenge to ICU intensivists and a heavy burden to public health [3].

Over the past decades, only a few approaches have been proven to be effective in reducing mortality in

\footnotetext{
* Correspondence: yiyiyang2004@163.com

Department of Critical Care Medicine, Zhongda Hospital, School of Medicine, Southeast University, Nanjing 210009, China
}

ARDS patients, including a lung-protective ventilation strategy [4-6] and prone positioning [7, 8]. Neuromuscular blocking agents (NMBAs) have been the only pharmaceutical approach that is supposed to benefit patients with ARDS.

In ARDS, an excessive respiratory drive could lead to increased tidal volume, voluntary exhalation, and patient-ventilation asynchrony, which potentially worsen ventilator-induced lung injury (VILI) and increase mortality [9]. NMBAs prevent the patient-initiated generation of high volumes and active exhalation, facilitate patient-ventilator synchrony, provide protection from VILI, and ultimately reduce mortality in patients with ARDS [10-12]. In addition, NMBAs are also reported to directly alleviate pulmonary and systemic inflammatory progression [13]. In the updated guideline for ARDS management, NMBAs are recommended for a subgroup

(C) The Author(s). 2020 Open Access This article is distributed under the terms of the Creative Commons Attribution 4.0 International License (http://creativecommons.org/licenses/by/4.0/), which permits unrestricted use, distribution, and reproduction in any medium, provided you give appropriate credit to the original author(s) and the source, provide a link to the Creative Commons license, and indicate if changes were made. The Creative Commons Public Domain Dedication waiver (http://creativecommons.org/publicdomain/zero/1.0/) applies to the data made available in this article, unless otherwise stated. 
of moderate-to-severe ARDS patients for early use in 48 to $72 \mathrm{~h} \mathrm{[14]}$. However, NMBA use and inappropriate sedation are also associated with ICU-acquired weakness, delayed ventilation weaning, and prolonged hospital stay [15-18].

Previous meta-analyses have demonstrated a significant decrease in mortality in ARDS patients by NMBA use $[19,20]$. However, in a recently published large-scale randomized trial in patients with moderate-to-severe ARDS, the early use of NMBAs in the first $48 \mathrm{~h}$ unexpectedly revealed no significant difference in mortality compared with usual care [21], which made NMBA use in ARDS further undetermined. Thus, it requires us for a quantitative analysis of the pooled results of up-to-date trials of NMBA use to validate the current effects of NMBAs in patients with moderate-to-severe ARDS. Furthermore, as the results between trials were inconsistent, we thought it might be necessary to investigate the reasons leading to the discrepancies in results for future study design and selection of patients that would potentially benefit from NMBA use in clinical practice.

\section{Methods}

This work was performed according to the Preferred Reporting Items for Systematic Reviews and Meta-Analyses (PRISMA) statement [22, 23] (Additional File 1) and was registered in the International Prospective Register of Systematic Reviews (PROSPERO, CRD42019138416).

\section{Information sources}

Two researchers independently searched several databases, including PubMed, EMBASE, Cochrane Central Register, and Web of Science up to June 1, 2019, and an updated search was conducted on November 14, 2019. When potentially relevant reviews or meta-analyses were found, a backward snowballing search was performed to obtain further studies.

\section{Search strategy}

The following key words were used in the search: "neuromuscular blocking agents," "neuromuscular blockers," "acute respiratory distress syndrome," "adult respiratory distress syndrome," and "shock lung." The full search strategy is included in Additional File 2.

\section{Eligibility criteria}

Trials that met the following criteria were included in this meta-analysis: (1) study population of moderate-tosevere ARDS patients diagnosed according to the Berlin criteria [24] or American-European Consensus Conference (AECC) criteria for ARDS [25]; (2) early use of an NMBA of any category, with no restrictions on the duration or dosage of the NMBA; (3) data on mortality were reported; and (4) randomized control trial (RCT) study design. The exclusion criteria were as follows: (1) duplicates or overlapping populations, (2) in vitro or animal experiments, (3) pediatric or pregnant subjects, (4) no ARDS patients, and (5) lack of data on mortality.

\section{Study selection}

Titles and abstracts were first reviewed separately by two researchers. When potentially relevant studies were found, the complete manuscripts were retrieved for further inspection. All the articles were reviewed, assessed, and selected by the two researchers independently with any disputes solved by consensus or consultation with a third researcher.

\section{Data items}

The following information was extracted from the studies: (1) subject characteristics (including age, sex, onset and origin of ARDS), (2) interventions (including NMBA regimen, sedation strategy, and mechanical ventilation mode), and (3) outcome measurements. The primary outcome was mortality, and the secondary outcomes were clinical outcomes, including partial pressure of arterial oxygen and carbon dioxide $\left(\mathrm{PaO}_{2}\right.$ and $\left.\mathrm{PaCO}_{2}\right)$, arterial $\mathrm{pH}, \mathrm{FiO}_{2}, \mathrm{PaO}_{2}$ to $\mathrm{FiO}_{2}$ ratio $\left(\mathrm{PaO}_{2} / \mathrm{FiO}_{2}\right)$, tidal volume, minute ventilation, peak inspiratory pressure (PIP), plateau pressure, respiratory rate, positive endexpiratory pressure (PEEP), driving pressure (DP), incidence of barotrauma, ICU-free days, and ventilationfree days.

The continuous variables were converted and are described as the mean with standard deviation (SD) if the median with interquartile range (IQR) or 95\% confidence interval (CI) were reported. If the clinical variables were reported at baseline and after treatment, the alterations in the variables from baseline to posttreatment were calculated using the methods described in Additional File 3. DP was calculated by subtracting PEEP from plateau pressure, which was calculated whenever possible, using the methods provided in Additional File 3.

\section{Risk of bias assessment}

Internal validity and risk of bias were assessed by two researchers separately following the Cochrane Collaboration's protocols [26]. The risk of bias of the articles was evaluated as "yes", "no," or "unclear" after scrutinizing the procedures performed in the articles.

\section{Summary measures}

Categorical variables are presented as proportions and were compared by risk ratios (RRs) with 95\% CIs. Continuous variables are described as the mean $\pm \mathrm{SD}$ and were compared by the mean difference (MD) or 
standard mean difference (SMD) according to the units of the variables.

\section{Statistical analysis}

The data extracted from the articles were analyzed by Review Manager 5.3 (The Nordic Cochrane Centre, Cochrane Collaboration, Copenhagen). Mantel-Haenszel statistics were applied for categorical variable measurements, and an inverse variance model was used for continuous variables. A random-effects model was deployed for a better accommodation of heterogeneity. Cochrane $I^{2}$ statistics were used to assess the statistical heterogeneity between studies, with $I^{2}>50 \%$ as high heterogeneity. Each study was sequentially removed, and the remaining dataset was reanalyzed for statistical significance or to detect favoring directions to evaluate the robustness of the results. Univariate meta-regression was used to explore the potential sources of heterogeneity. Post hoc sub-group analysis was conducted to analyze the effects of NMBA on subpopulation of patients. Funnel plots were used to evaluate the publication bias of the studies by visual inspection.

Trial sequential analysis (TSA) was deployed to calculate the optimal information size [27] and was analyzed by Copenhagen Trial Unit's Trial Sequential Analysis software (Copenhagen Trial Unit, Copenhagen). We estimated $36 \%$ mortality in the control arm and a reduction of mortality to $27 \%$ in the NMBA arm, adopted from the ACURASYS study [10], with $80 \%$ power and a two-sided alpha of 0.05 . We inspected the Lan-DeMets sequential monitoring boundary and the current information size to determine whether the optimal information size was reached. A two-tailed $P$ value less than 0.05 was considered statistically significant.

\section{Results}

\section{Study selection and characteristics}

The comprehensive search yielded a total of 871 articles, and 7 randomized trials enrolling 1598 patients were finally included in this meta-analysis [10, 21, 28-32] (Fig. 1). Among the enrolled studies, three studies adopted the AECC criteria $[10,28,29]$ and the remaining four used Berlin criteria [21, 30-32] for ARDS diagnosis. All studies used deep sedations with a Ramsay score of 6 in the control group, except for the ROSE study [21] and study by Rao et al. [32], in which light sedation with a Richmond Agitation-Sedation Scale (RASS) score of 0 to -1 and a Ramsay score of 2 to 4 were used in the control arm respectively (Table 1). The detailed risk bias assessment of the trials is provided in Additional File 4.

\section{Synthesis of results}

\section{Primary outcomes}

The data on mortality extracted from the trials were pooled and analyzed, and the results revealed a

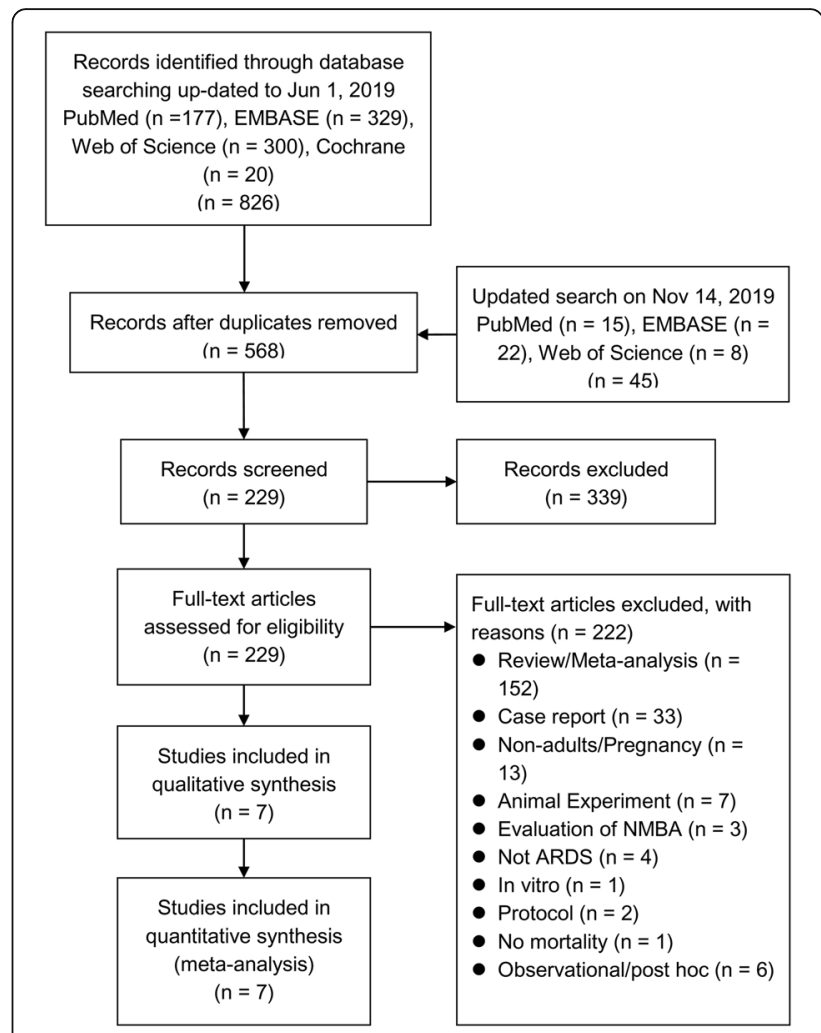

Fig. 1 Flow chart of the search process and study selection

significant decrease in mortality in the NMBA group compared with the control group, with an RR of 0.74 (95\% CI 0.56 to $0.98, P=0.03$ ), when the observation endpoint was truncated to day 28 . The decrease in mortality in the NMBA group could still be observed, with an RR of 0.77 (95\% CI 0.60 to $0.99, P=0.04$ ), when truncated to day 90 (Fig. 2).

\section{Secondary outcomes}

We compared the clinical outcomes between the NMBA and control groups and found that the use of NMBAs significantly increased the $\mathrm{PaO}_{2} / \mathrm{FiO}_{2}$ ratio change (mmHg, MD 8.97, 95\% CI 0.66 to $17.28, P=0.03$ ); reduced $\mathrm{FiO}_{2}$ by approximately $4 \%(\mathrm{MD}-0.04,95 \% \mathrm{CI}-$ 0.09 to $0.00, P=0.03$ ); decreased the minute ventilation change $(\mathrm{L} / \mathrm{min}, \mathrm{MD}-0.51,95 \% \mathrm{CI}-0.76$ to $-0.07, P=$ 0.02); and decreased the PEEP level change $\left(\mathrm{cmH}_{2} \mathrm{O}\right.$, MD $-0.52,95 \%$ CI -1.01 to $-0.03, P=0.04$ ). The use of NMBAs also decreased the incidence of barotrauma in mechanical ventilation (RR $0.56,95 \%$ CI 0.36 to 0.87 , $P=0.009$ ). We found a significant increase in DP in patients using NMBAs $\left(\mathrm{cmH}_{2} \mathrm{O}, \mathrm{MD} 0.91,95 \% \mathrm{CI} 0.37\right.$ to $1.45, P=0.001$ ).

No significant differences could be observed in the other respiratory physiological parameters, ICU-free days $(P=0.74)$ or ventilation-free days $(P=0.19$ when truncated to day $28, P=0.09$ when truncated to day 90 ) 
Table 1 Baseline characteristics of the included trials

\begin{tabular}{|c|c|c|c|c|c|c|}
\hline Study & $\begin{array}{l}\text { Patients } \\
\text { no. } \\
\text { (sites) }\end{array}$ & Target patients & NMBA group & $\begin{array}{l}\text { Control } \\
\text { group }\end{array}$ & Ventilation strategy & Sedation target \\
\hline $\begin{array}{l}\text { Gainnier } \\
\text { et al. [28] }\end{array}$ & $56(4)$ & $\begin{array}{l}\text { AECC criteria for ARDS } \\
\text { with } \mathrm{PaO}_{2} / \mathrm{FiO}_{2} \text { ratio } \\
<150 \text { at a } \mathrm{PEEP} \geq 5 \mathrm{~cm} \\
\mathrm{H}_{2} \mathrm{O} \text { within } 36 \mathrm{~h}\end{array}$ & $\begin{array}{l}\text { One bolus of } 50 \mathrm{mg} \text { of } \\
\text { cisatracurium infusion, } \\
\text { followed by a continuous } \\
\text { infusion at an initial rate of } \\
5 \mathrm{\mu g} / \mathrm{kg} \text { per min for } 48 \mathrm{~h}\end{array}$ & $\begin{array}{l}\text { An infusion } \\
\text { of saline at a } \\
\text { rate of } 4 \\
\mathrm{~mL} / \mathrm{h}\end{array}$ & $\begin{array}{l}\text { Assist-control mode for at least } \\
48 \mathrm{~h} \text {. Tidal volume } 6-8 \mathrm{~mL} / \mathrm{kg} \text { of } \\
\text { ideal body weight }\end{array}$ & $\begin{array}{l}\text { Midazolam and } \\
\text { sufentanil to obtair } \\
\text { a Ramsay score } \\
\text { of } 6\end{array}$ \\
\hline $\begin{array}{l}\text { Forel } \\
\text { et al. [29] }\end{array}$ & $36(3)$ & $\begin{array}{l}\text { AECC criteria for ARDS } \\
\text { with } \mathrm{PaO}_{2} / \mathrm{FiO}_{2} \text { ratio } \\
<200 \mathrm{mmHg}^{2} \text { a a PEEP } \\
\geq 5 \mathrm{~cm} \mathrm{H}_{2} \mathrm{O} \text { within } 48 \mathrm{~h} \\
\text { of onset }\end{array}$ & $\begin{array}{l}\text { One bolus of } 50 \mathrm{mg} \text { of } \\
\text { cisatracurium infusion, } \\
\text { followed by a continuous } \\
\text { infusion at an initial rate of } \\
5 \mathrm{\mu g} / \mathrm{kg} \text { per min for } 48 \mathrm{~h}\end{array}$ & $\begin{array}{l}\text { An infusion } \\
\text { of saline at a } \\
\text { rate of } 4 \\
\mathrm{~mL} / \mathrm{h}\end{array}$ & $\begin{array}{l}\text { Assist/control-volume with a tidal } \\
\text { volume of } 4-8 \mathrm{~mL} / \mathrm{kg} \text { predicted } \\
\text { body weight and a plateau } \\
\text { pressure of } \leq 30 \mathrm{~cm} \mathrm{H} \mathrm{H}_{2} \mathrm{O}\end{array}$ & $\begin{array}{l}\text { Midazolam } \\
(3-30 \mathrm{mg} / \mathrm{h}) \text { and } \\
\text { sufentanil } \\
\text { (10-150 } \mathrm{\mu g} / \mathrm{h}) \text { to } \\
\text { obtain a Ramsay } \\
\text { score of } 6\end{array}$ \\
\hline $\begin{array}{l}\text { Papazian } \\
\text { et al. [10] }\end{array}$ & $\begin{array}{l}339 \\
(12)\end{array}$ & $\begin{array}{l}\text { AECC criteria for ARDS } \\
\text { with } \mathrm{PaO}_{2} / \mathrm{FiO}_{2} \text { ratio } \\
<150 \mathrm{mmHg}^{2} \text { at a PEEP } \\
\geq 5 \mathrm{~cm} \mathrm{H}_{2} \mathrm{O} \text { within } 48 \mathrm{~h}\end{array}$ & $\begin{array}{l}\text { One bolus infusion of } 15 \mathrm{mg} \text { of } \\
\text { cisatracurium, followed by a } \\
\text { continuous infusion of } 37.5 \mathrm{mg} \\
\text { per hour for } 48 \mathrm{~h}\end{array}$ & $\begin{array}{l}\text { An infusion } \\
\text { of saline at } \\
\text { the same } \\
\text { rate as } \\
\text { NMBA } \\
\text { group }\end{array}$ & $\begin{array}{l}\text { Volume assist-control mode, with } \\
\text { a tidal volume of } 6 \text { to } 8 \mathrm{~mL} \text { per } \\
\text { kilogram of predicted body } \\
\text { weight }\end{array}$ & $\begin{array}{l}\text { Obtain a Ramsay } \\
\text { score of } 6\end{array}$ \\
\hline $\begin{array}{l}\text { Lyu et al. } \\
{[30]}\end{array}$ & $96(1)$ & $\begin{array}{l}\text { Moderate to severe } \\
\text { ARDS with a PaO2/FiO2 } \\
\text { less than } 150 \text { with PEEP } \\
\text { at least } 5 \text { within the } \\
\text { first } 48 \mathrm{~h}\end{array}$ & $\begin{array}{l}\text { One bolus infusion of } \\
0.1 \mathrm{mg} / \mathrm{kg} \text { vecuronium, } \\
\text { followed by a continuous } \\
\text { infusion of } 0.05 \mathrm{mg} / \mathrm{kg} \text { per } \\
\text { hour for } 24 \text { to } 48 \mathrm{~h}\end{array}$ & Usual care & $\begin{array}{l}\text { Volume control mode, with a } \\
\text { tidal volume of } 4 \text { to } 8 \mathrm{~mL} \text { per } \\
\text { kilogram of predicted body } \\
\text { weight }\end{array}$ & $\begin{array}{l}\text { Sedation of } \\
\text { midazolam and } \\
\text { sufentanil }\end{array}$ \\
\hline $\begin{array}{l}\text { Rao et al. } \\
\text { [32] }\end{array}$ & $41(1)$ & $\begin{array}{l}\text { Berlin criteria for } \\
\text { moderate-to-severe } \\
\text { ARDS }\end{array}$ & $\begin{array}{l}\text { Continuous infusion of } \\
1 \mu \mathrm{g} / \mathrm{kg} \text { per min of } \\
\text { vecuronium }\end{array}$ & Usual care & $\begin{array}{l}\text { Protective ventilation strategy, } \\
\text { with a tidal volume of } 6 \mathrm{~mL} \text { per } \\
\text { kilogram of ideal predicted body } \\
\text { weight, with a plateau pressure } \\
\leq 30 \mathrm{~cm} \mathrm{H} \mathrm{H} O\end{array}$ & $\begin{array}{l}\text { Midazolam and } \\
\text { sufentanil or } \\
\text { midazolam and } \\
\text { fentanyl with a } \\
\text { Ramsay score of } 2 \\
\text { to } 4\end{array}$ \\
\hline $\begin{array}{l}\text { Guervilly } \\
\text { et al. [31] }\end{array}$ & $24(2)$ & $\begin{array}{l}\text { Moderate to severe } \\
\text { ARDS with a PaO2/FiO2 } \\
\text { less than } 150 \text { with PEEP } \\
\text { at least } 5 \text { within the first } \\
48 \mathrm{~h}\end{array}$ & $\begin{array}{l}\text { Cisatracurium besylate was } \\
\text { given using a } 3-\mathrm{mL} \text { rapid intra } \\
\text { venous infusion of } 15 \mathrm{mg} \\
\text { followed by a continuous } \\
\text { infusion of } 37.5 \mathrm{mg} / \mathrm{h}\end{array}$ & Usual care & $\begin{array}{l}\text { Volume-assist control mode with } \\
\text { a tidal volume of } 6 \mathrm{~mL} / \mathrm{kg} / \mathrm{IPBW} \\
\text { (ideal predicted body weight) }\end{array}$ & $\begin{array}{l}\text { Midazolam and } \\
\text { sufentanil to } \\
\text { achieve a Ramsay } \\
\text { score of } 6\end{array}$ \\
\hline $\begin{array}{l}\text { Moss } \\
\text { et al. [21] }\end{array}$ & $\begin{array}{l}1006 \\
(48)\end{array}$ & $\begin{array}{l}\text { present for less than } 48 \\
\text { h: PaO2:FiO2 of less } \\
\text { than } 150 \mathrm{mmHg} \text { with a } \\
\text { PEEP of } 8 \mathrm{~cm} \text { or more of } \\
\text { water }\end{array}$ & $\begin{array}{l}\text { An intravenous bolus of } 15 \mathrm{mg} \\
\text { of cisatracurium, followed by a } \\
\text { continuous infusion of } 37.5 \mathrm{mg} \\
\text { per hour for } 48 \mathrm{~h}\end{array}$ & $\begin{array}{l}\text { An infusion } \\
\text { of saline at } \\
\text { the same } \\
\text { rate as } \\
\text { NMBA } \\
\text { group }\end{array}$ & $\begin{array}{l}\text { Protective ventilation strategy, } \\
\text { with a tidal volume of } 6 \mathrm{~mL} \text { per } \\
\text { kilogram of ideal predicted body } \\
\text { weight, with a PEEP } \geq 8 \mathrm{cmH} 2 \mathrm{O}\end{array}$ & $\begin{array}{l}\text { A RASS score of } 0 \\
\text { or }-1 \text { in the } \\
\text { control group }\end{array}$ \\
\hline
\end{tabular}

between the NMBA and control groups. The full list of comparisons of the clinical outcomes was provided in Additional File 5.

\section{Risk of bias and sensitivity analysis}

We used both fixed-effects and random-effects models to retest the results, and we found no changes in favoring directions in either model. However, when each trial was sequentially omitted from the meta-analysis to analyze the individual effects of the trial on the overall results, the results showed that the significance was lost when some studies were omitted from the pooled analysis (Additional File 6). Visual inspection indicated asymmetry in the funnel plot, which indicated potential publication bias (Additional File 7).

\section{Meta-regression and subgroup analysis}

We conducted a univariate meta-regression and found that the publishing year $(P=0.037)$, sample size $(P=$ 0.036 ), and sedation strategy (deep vs. light sedation, $P=0.049$ ) might associate with the heterogeneity between studies. Furthermore, the estimated improvement of $\mathrm{PaO}_{2}$ to $\mathrm{FiO}_{2}$ ratio $24 \mathrm{~h}$ after enrollment yielded a $P$ value of 0.062 . The full list of factors involved in the meta-regression was provided in Additional File 8. A post hoc sub-group analysis was deployed and found that patients diagnosed according to AECC criteria (RR $0.66,95 \%$ CI 0.50 to $0.87, P=0.003$ ), patients with $\mathrm{PaO} 2$ to $\mathrm{FiO} 2$ ratio less than $150 \mathrm{mmHg}$ at enrollment (RR $0.72,95 \%$ CI 0.53 to $0.97, P=0.03$ ), and patients with deep sedation strategy (RR $0.66,95 \%$ CI 0.51 to 0.84 , $P=0.001$ ) were likely to benefit from NMBA use (see Additional File 9). 


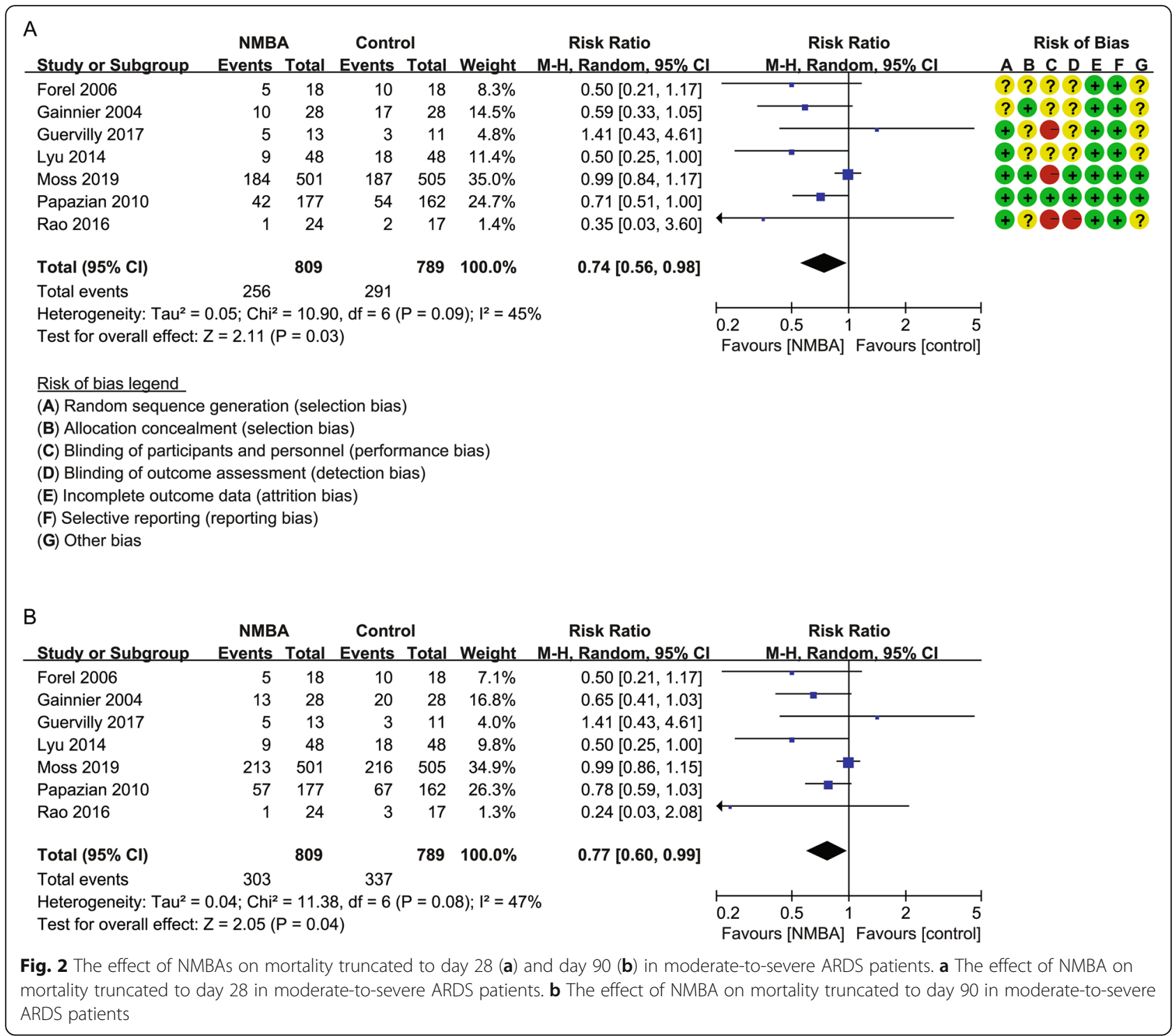

\section{Trial sequential analysis}

Trial sequential analysis was performed in the study, and the results indicated that the current information size did not cross the Lan-DeMets sequential monitoring boundary constructed by the optimal information size, indicating insufficient sample size in investigating the mortality truncated to day 28. An optimal sample size of 3454 patients was estimated, which was supposed to reach the plausible endpoint (Fig. 3).

\section{Discussion}

In the present meta-analysis, we pooled the results from 7 trials enrolling 1598 patients to validate the use of NMBAs in patients with moderate-to-severe ARDS and found that the early use of NMBAs in the first $48 \mathrm{~h}$ could significantly reduce mortality truncated to day 28 (RR 0.74, 95\% CI 0.56 to $0.98, P=0.03$ ) and to day 90
(RR $0.77,95 \%$ CI 0.60 to $0.99, P=0.04$ ). The use of NMBAs was associated with improved respiratory parameters, including increased $\mathrm{PaO}_{2} / \mathrm{FiO}_{2}$ ratio and reduced $\mathrm{FiO}_{2}$, minute ventilation, PEEP level, and incidence of barotrauma during mechanical ventilation (RR $0.56,95 \%$ CI 0.36 to $0.87, P=0.009$ ). We also found an increased measurement of DP after NMBA use ( $\mathrm{cmH}_{2} \mathrm{O}, \mathrm{MD} 0.91,95 \% \mathrm{CI} 0.37$ to $\left.1.45, P=0.001\right)$.

Our results were consistent with previous findings that the use of NMBAs could significantly reduce mortality in patients with moderate-to-severe ARDS [19, 20]. NMBA use was associated with facilitated patientventilator synchrony, which potentially reduces the incidence of VILI and barotrauma and ultimately improves outcomes in ARDS patients.

We found a significant increase in DP in the NMBA group compared with the control group $\left(\mathrm{cmH}_{2} \mathrm{O}, \mathrm{MD}\right.$ 


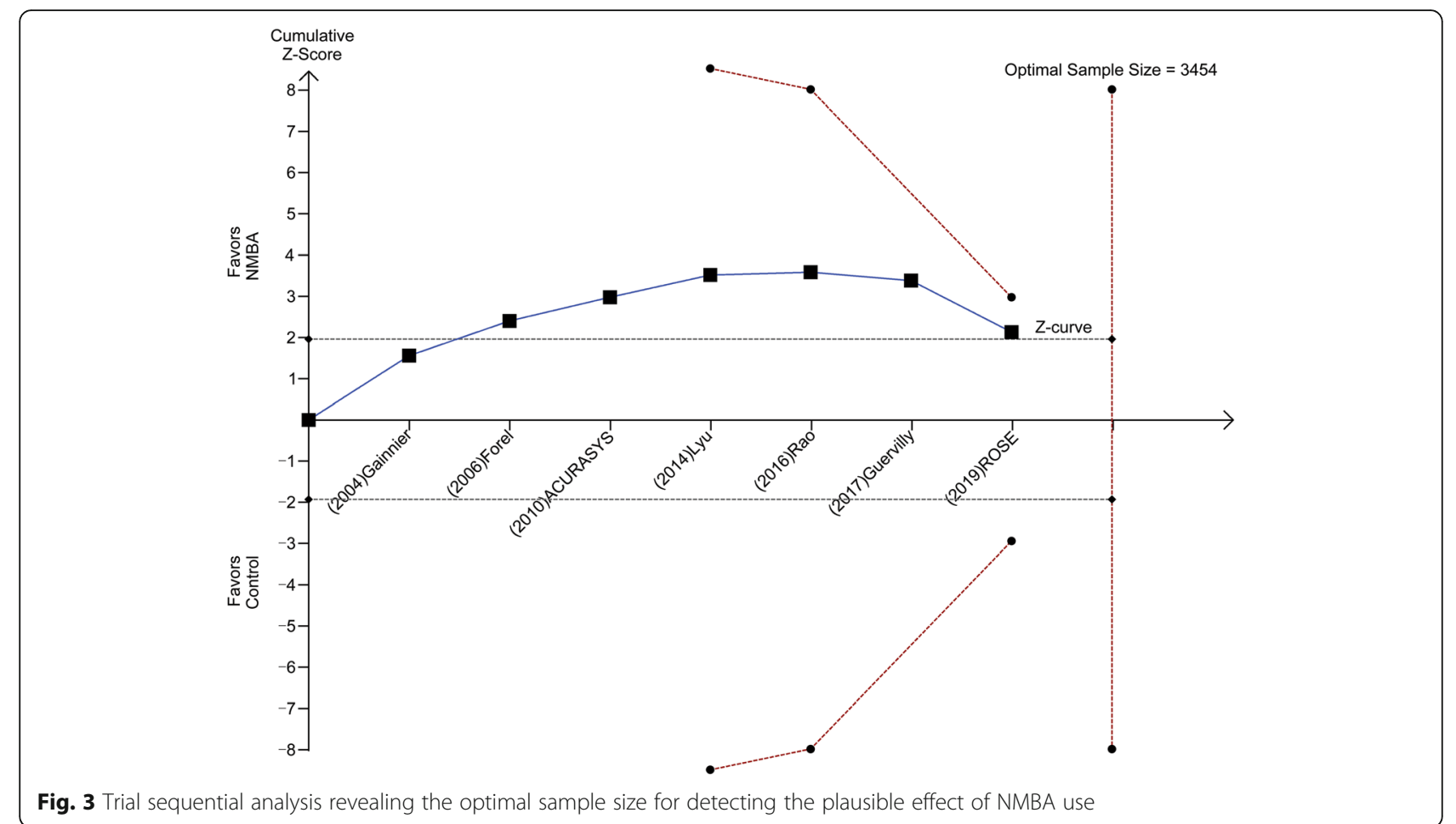

$0.91,95 \%$ CI 0.36 to $1.45, P=0.001$ ). We speculated that this finding may be due to the existence of spontaneous breath in the control group, which led to the inaccurate measurement of DP.

However, sensitivity analysis suggested that our result was not robust and Cochrane $I^{2}$ statistics indicated certain heterogeneity between studies $\left(I^{2}=45 \%\right)$.

Sedation strategy might be one of the sources of heterogeneity. Sub-group analysis suggested that ARDS patients underwent deep sedation was more likely to benefit from NMBA use (RR 0.66, 95\% CI 0.51 to 0.84 , $P=0.001$ ). We thought this could be partially explained by the effects of reverse triggering, defined as a diaphragm contraction triggered by mechanical ventilation, which could lead to breath stacking, VILI, and barotrauma [33]. Reverse triggering was paradoxically seen in ARDS patients with deep sedation and could be resolved by NMBA use [34]. It was possible that in the trials included in the present meta-analysis, the patients in the control group with deep sedation would have reverse triggering and thus worse outcomes, and the use of NMBAs could resolve the deleterious effect of reverse triggering, while in studies in which light sedation was used in the control group, reverse triggering was mitigated, which might have masked the effects of NMBA use [35, 36].

We saw a tendency of statistical significance by metaregression that the resolve of $\mathrm{PaO}_{2} / \mathrm{FiO}_{2}$ ratio on the second day after enrollment was likely to contribute to the source of heterogeneity $(P=0.062)$. We speculated that the ARDS patients who had a greater improvement in $\mathrm{PaO}_{2} / \mathrm{FiO}_{2}$ ratio were probably not as severe or at least not as refractory reversible, which suggested that the use of NMBAs might be beneficial in patients with extremely refractory and severe ARDS.

We also noticed a significant effect of NMBA use in a sub-group of ARDS patients with a $\mathrm{PaO}_{2} / \mathrm{FiO}_{2}$ ratio less than or equal to $150 \mathrm{mmHg}$ at enrollment (RR 0.72, 95\% CI 0.53 to $0.97, P=0.03$ ). However, as the disparity of the number of patients in each sub-group was great, this result should be interpreted with much caution. Furthermore, meta-regression suggested that the year in which the study was published also introduced heterogeneity $(P=0.037)$ and we found NMBA use was effective in the ACEE definition for ARDS (RR 0.66, 95\% CI 0.50 to $0.87, P=0.003)$. However, we did not regard the definition for ARDS as a confounding factor and we would rather believe this could probably due to the evolvement of ARDS management, which seemed to make NMBA use less important. NMBA was not a "magic bullet" and should be a part of a lung-protective strategy.

The current results may not be conclusive. We then conducted TSA; the results indicated that more patients were needed to validate the use of NMBAs in ARDS, with an optimal sample size of 3454 patients.

Our study had several limitations. Some trials included in the meta-analysis were of limited sample size, which was likely to bring bias to the results, and only two 
large-scale randomized trials were included in our metaanalysis. More trials are needed to further validate the effects of NMBAs in ARDS. We used a mathematical imputation method to calculate the variables with the after-before alterations of certain parameters, which would potentially bring bias to the results and the interpretations. Some of the subgroup analyses included only two studies, which could potentially bring bias to the results and should be interpreted cautiously.

\section{Conclusion}

Early use of NMBAs could reduce mortality and decrease the incidence of barotrauma during mechanical ventilation in patients with moderate-to-severe ARDS. However, more RCTs are needed to further validate the effects of NMBAs in ARDS.

\section{Supplementary information}

Supplementary information accompanies this paper at https://doi.org/10. 1186/s13054-020-2765-2

Additional file 1. Checklist for systematic reviews applied on this manuscript according to the Preferred Reporting Items for Systematic reviews and Meta-Analysis (PRISMA).

Additional file 2. Full list of search strategy for PubMed.

Additional file 3. Data transformation and missing data imputations.

Additional file 4. Risk of bias assessment of the included trials.

Additional file 5. Secondary outcome analysis, including $\mathrm{PaO} 2$ to $\mathrm{FiO}_{2}$ ratio, $\mathrm{PaO} 2$, arterial $\mathrm{pH}$, FiO2, PIP, Pplat, tidal volume, PEEP, minute ventilation, DP, MRC score, respiratory rate, barotrauma, ICU-free days and ventilation-free days.

Additional file 6 . Sensitivity analysis.

Additional file 7. Publication bias by funnel plot.

Additional file 8. Univariate meta-regression analysis. Following factors were used for meta-regression, publishing year, sample size, language (English or Chinese), ARDS definition (AECC or Berlin criteria), estimated average $\mathrm{PaO} 2$ to $\mathrm{FiO} 2$ ratio of ARDS patients at enrollment, estimated average improvement of $\mathrm{PaO} 2$ to $\mathrm{FiO} 2$ ratio 24 hours after enrollment, quality of the study, percentage of patients with intra-pulmonary etiology, sedation strategy (light or deep).

Additional file 9. Sub-group analysis. Patients were divided by ARDS definition (AECC or Berlin), initial PEEP setting $(<=10 \mathrm{mmHg}$ vs $>$ $10 \mathrm{mmHg}), \mathrm{PaO} 2$ to $\mathrm{FiO} 2$ ratio at enrollment $(<=150 \mathrm{mmHg}$ vs $>$ $150 \mathrm{mmHg}$ ) and sedation strategy (light vs deep sedation).

\section{Abbreviations}

AECC: American-European Consensus Conference; ARDS: Acute respiratory distress syndrome; Cl: Confidence interval; DP: Driving pressure; ICU: Intensive care unit; IQR: Interquartile range; MD: Mean difference; NMBA: Neuromuscular blocking agent; OR: Odds ratio; PEEP: Positive endexpiratory pressure; PIP: Peak inspiratory pressure; PROSPERO: International Prospective Register of Systemic Reviews; RASS: Richmond AgitationSedation Scale; RCT: Randomized control trial; SD: Standard deviation; SMD: Standard mean difference; TSA: Trial sequential analysis

\section{Acknowledgements}

Not applicable

\section{Authors' contributions}

WC carried out the analysis and interpretation of data and participated in drafting, editing, and submitting the manuscript. The articles were reviewed by two reviewers (WC and QS) independently in accordance with the inclusion criteria. Disagreements were resolved by consensus and discussion including a third reviewer (FP). The quality of the articles was assessed by WC and JX independently, with disagreements resolved by consulting a third reviewer (QS). YY and $\mathrm{HQ}$ were responsible for the conception, design, and coordination of the study and for revising the manuscript for important intellectual content. The author(s) read and approved the final manuscript.

\section{Funding}

This work was partially supported by Jiangsu Province's Key Discipline/ Laboratory of Medicine (ZDXKA2016025), Jiangsu Province's Key Provincial Talents Program (ZDRCA2016082), and the Jiangsu Provincial Key Research and Development Program (SBE2018750279).

\section{Availability of data and materials}

The datasets used and/or analyzed during the current study are available from the corresponding author upon reasonable request.

\section{Ethics approval and consent to participate}

Not applicable

\section{Consent for publication}

Not applicable

\section{Competing interests}

The authors declare that they have no competing interests.

Received: 11 October 2019 Accepted: 7 February 2020

Published online: 17 February 2020

\section{References}

1. Sweeney RM, McAuley DF. Acute respiratory distress syndrome. Lancet. 2016:388(10058):2416-30.

2. Thompson BT, Chambers RC, Liu KD. Acute respiratory distress syndrome. N Engl J Med. 2017;377(6):562-72.

3. Bellani G, Laffey JG, Pham T, et al. Epidemiology, patterns of care, and mortality for patients with acute respiratory distress syndrome in intensive care units in 50 countries. JAMA. 2016;315(8):788-800.

4. Brower RG, Lanken PN, Maclntyre N, et al. Higher versus lower positive endexpiratory pressures in patients with the acute respiratory distress syndrome. N Engl J Med. 2004:351(4):327-36.

5. Acute Respiratory Distress Syndrome N, Brower RG, Matthay MA, et al. Ventilation with lower tidal volumes as compared with traditional tidal volumes for acute lung injury and the acute respiratory distress syndrome. N Engl J Med. 2000;342(18):1301-8.

6. Amato MB, Meade MO, Slutsky AS, et al. Driving pressure and survival in the acute respiratory distress syndrome. N Engl J Med. 2015;372(8):747-55.

7. Guerin C, Reignier J, Richard JC, et al. Prone positioning in severe acute respiratory distress syndrome. N Engl J Med. 2013;368(23):2159-68.

8. Hu SL, He HL, Pan C, et al. The effect of prone positioning on mortality in patients with acute respiratory distress syndrome: a meta-analysis of randomized controlled trials. Crit Care. 2014;18(3):R109.

9. Blanch L, Villagra A, Sales B, et al. Asynchronies during mechanical ventilation are associated with mortality. Intensive Care Med. 2015;41(4): 633-41.

10. Papazian L, Forel JM, Gacouin A, et al. Neuromuscular blockers in early acute respiratory distress syndrome. N Engl J Med. 2010;363(12):1107-16.

11. Slutsky AS. Neuromuscular blocking agents in ARDS. N Engl J Med. 2010; 363(12):1176-80.

12. Beitler JR, Sands SA, Loring SH, et al. Quantifying unintended exposure to high tidal volumes from breath stacking dyssynchrony in ARDS: the BREATHE criteria. Intensive Care Med. 2016;42(9):1427-36.

13. Fanelli V, Morita Y, Cappello P, et al. Neuromuscular blocking agent cisatracurium attenuates lung injury by inhibition of nicotinic acetylcholine receptor-alpha1. Anesthesiology. 2016;124(1):132-40.

14. Chiumello D, Brochard L, Marini JJ, et al. Respiratory support in patients with acute respiratory distress syndrome: an expert opinion. Crit Care. 2017; 21(1):240.

15. Kress JP, Pohlman AS, O'Connor MF, et al. Daily interruption of sedative infusions in critically ill patients undergoing mechanical ventilation. N Engl J Med. 2000;342(20):1471-7. 
16. Shehabi Y, Bellomo R, Reade MC, et al. Early intensive care sedation predicts long-term mortality in ventilated critically ill patients. Am J Respir Crit Care Med. 2012;186(8):724-31.

17. Hermans G, Van den Berghe G. Clinical review: intensive care unit acquired weakness. Crit Care. 2015;19:274.

18. Devlin JW, Skrobik Y, Gelinas C, et al. Clinical practice guidelines for the prevention and management of pain, agitation/sedation, delirium, immobility, and sleep disruption in adult patients in the ICU. Crit Care Med. 2018:46(9):e825-e73.

19. Alhazzani W, Alshahrani M, Jaeschke R, et al. Neuromuscular blocking agents in acute respiratory distress syndrome: a systematic review and meta-analysis of randomized controlled trials. Crit Care. 2013;17(2):R43.

20. Tao W, Yang LQ, Gao J, et al. Neuromuscular blocking agents for adult patients with acute respiratory distress syndrome: a meta-analysis of randomized controlled trials. J Trauma Acute Care Surg. 2018:85(6):1102-9.

21. Moss M, Huang DT, Brower RG, et al. Early neuromuscular blockade in the acute respiratory distress syndrome. N Engl J Med. 2019;380(21):1997-2008.

22. Moher D, Liberati A, Tetzlaff J, et al. Preferred reporting items for systematic reviews and meta-analyses: the PRISMA statement. BMJ. 2009;339:b2535.

23. Liberati A, Altman DG, Tetzlaff J, et al. The PRISMA statement for reporting systematic reviews and meta-analyses of studies that evaluate healthcare interventions: explanation and elaboration. BMJ. 2009;339:b2700.

24. Force ADT, Ranieri VM, Rubenfeld GD, et al. Acute respiratory distress syndrome: the Berlin definition. JAMA. 2012;307(23):2526-33.

25. Bernard GR, Artigas A, Brigham KL, et al. The American-European consensus conference on ARDS. Definitions, mechanisms, relevant outcomes, and clinical trial coordination. Am J Respir Crit Care Med. 1994;149(3 Pt 1):818-24.

26. Higgins JP, Altman DG, Gotzsche PC, et al. The Cochrane Collaboration's tool for assessing risk of bias in randomised trials. BMJ. 2011;343:d5928.

27. Pogue JM, Yusuf S. Cumulating evidence from randomized trials: utilizing sequential monitoring boundaries for cumulative meta-analysis. Control Clin Trials. 1997;18(6):580-93 discussion 661-6.

28. Gainnier M, Roch A, Forel JM, et al. Effect of neuromuscular blocking agents on gas exchange in patients presenting with acute respiratory distress syndrome. Crit Care Med. 2004:32(1):113-9.

29. Forel JM, Roch A, Marin V, et al. Neuromuscular blocking agents decrease inflammatory response in patients presenting with acute respiratory distress syndrome. Crit Care Med. 2006;34(11):2749-57.

30. Lyu G, Wang $X$, Jiang $W$, et al. Clinical study of early use of neuromuscular blocking agents in patients with severe sepsis and acute respiratory distress syndrome. Zhonghua Wei Zhong Bing Ji Jiu Yi Xue. 2014;26(5):325-9.

31. Guervilly C, Bisbal M, Forel JM, et al. Effects of neuromuscular blockers on transpulmonary pressures in moderate to severe acute respiratory distress syndrome. Intensive Care Med. 2017;43(3):408-18.

32. Rao Z, Li J, Yan M, et al. To retain spontaneous breathing or eliminate spontaneous breathing with neuromuscular blockers in acute respiratory distress syndrome patients? Zhonghua Wei Zhong Bing Ji Jiu Yi Xue. 2016; 28(11):973-7.

33. Akoumianaki E, Lyazidi A, Rey N, et al. Mechanical ventilation-induced reverse-triggered breaths: a frequently unrecognized form of neuromechanical coupling. Chest. 2013;143(4):927-38.

34. Bourenne J, Guervilly C, Mechati $\mathrm{M}$, et al. Variability of reverse triggering in deeply sedated ARDS patients. Intensive Care Med. 2019;45(5):725-6.

35. Torbic H, Krishnan S, Duggal A. Neuromuscular blocking agents for acute respiratory distress syndrome: how did we get conflicting results? Crit Care. 2019;23(1):305

36. Slutsky AS, Villar J. Early paralytic agents for ARDS? Yes, no, and sometimes. N Engl J Med. 2019;380(21):2061-3.

\section{Publisher's Note}

Springer Nature remains neutral with regard to jurisdictional claims in published maps and institutional affiliations.

\section{Ready to submit your research? Choose BMC and benefit from:}

- fast, convenient online submission

- thorough peer review by experienced researchers in your field

- rapid publication on acceptance

- support for research data, including large and complex data types

- gold Open Access which fosters wider collaboration and increased citations

- maximum visibility for your research: over $100 \mathrm{M}$ website views per year

At $\mathrm{BMC}$, research is always in progress.

Learn more biomedcentral.com/submissions 